\title{
Calcium Oxalate Crystal Measurement
}

National Cancer Institute

\section{Source}

National Cancer Institute. Calcium Oxalate Crystal Measurement. NCI Thesaurus. Code C74670.

The determination of the amount of calcium oxalate crystals present in a sample. 